\title{
ÓRTESES PARA CRIANÇAS COM PARALISIA CEREBRAL: UMA REVISÃO DE LITERATURA
}

\author{
ORTHESIS FOR CHILDREN WITH CEREBRAL PALSY: A LITERATURE REVIEW \\ Flávia Carolina L. da Silva ${ }^{1}$, Rafaela G. S. Pedrosa Simesa ${ }^{1}$, lone Cristine Rocha Izídio ${ }^{1}$, Lílian \\ Aparecida da Silva ${ }^{2}$, Paulo Henrique de Melo ${ }^{1}$ \\ Faculdade Facottur, Olinda/PE.
}

\begin{abstract}
The aim of the present study was to expand knowledge about the evidence on orthosis prescriptions for children with cerebral palsy. MATERIALS AND METHODS: A narrative literature review was carried out through electronic databases, in addition to research in books and scientific magazines. Orthoses for children with (CP) act in a beneficial way in the rehabilitation process in addition to physical benefits, and work to prevent deformities by controlling spasticity, for example, helping the child to be independent in the activities of daily life. The present study provides us with a broader knowledge about the different types of orthoses, where the analyzed data allow us to observe that the most suitable for children in the treatment of CP are the AFOs.
\end{abstract}

Keywords: Cerebral palsy, Orthotic devices, Physical therapy specialty.
Resumo

$O$ objetivo do presente estudo foi ampliar $o$ conhecimento acerca das evidências sobre as prescrições de órteses para crianças com paralisia cerebral. Foi realizada uma revisão narrativa de literatura por meio de bancos de dados eletrônicos, além de pesquisas em livros $e$ revistas científicas. As Órteses para crianças com (PC) agem de maneira benéfica no processo de reabilitação além dos benefícios físicos, e atua prevenindo as deformidades através do controle da espasticidade, por exemplo, contribuindo para que a criança possa ser independente nas atividades de vida diária. Este estudo nos possibilita um conhecimento mais amplo sobre os diversos tipos de órteses, onde os dados analisados nos permitem observar que as mais indicadas para crianças no tratamento da $P C$ são as AFOs.

Palavras-chave: Paralisia cerebral; Aparelhos ortopédicos, Fisioterapia. 


\section{Introdução}

Segundo Souza ${ }^{1}$, a paralisia cerebral (PC) é determinada como um conjunto de desordens motoras secundárias a uma lesão estática ou malformação que acontece durante o desenvolvimento encefálico. São existentes quatro tipos de PC, a paralisia cerebral espástica, a paralisia cerebral discinética, a paralisia cerebral atáxica e a paralisia cerebral mista, essas desordens ou malformação acabam gerando alterações motoras e posturais unilaterais, bilaterais ou em partes isoladas que levam a manifestações clínicas variadas, que acometem, ou não a área cognitiva.

A prevalência da PC de acordo com os estudos epidemiológicos que vem sendo realizados há décadas, em países como Estados Unidos e Suécia é de aproximadamente 2 a 3 por 1000 crianças nascidas vivas. o cálculo é feito levando em consideração às crianças em idade escolar e que frequentam os centros de reabilitação ${ }^{2}$. No Brasil, é estimada a ocorrência de 30.000 a 40.000 casos novos por ano, em relação aos tipos de $\mathrm{PC}$, a espástica encontra-se como a forma mais presente compreendendo $70 \%$ dos casos, seguida pela forma extrapiramidal (20\%) dos casos e por último como a forma menos frequente encontra-se a PC atáxica $(10 \%)^{3}$.

$\mathrm{Na}$ visão de Rothstein ${ }^{4}$, os fatores de risco da PC estão ligados a causas voltadas para os períodos pré, peri ou pós-natais, sendo multifatorial, estando as possíveis causas ligadas a hipóxia durante o parto, leucomalácia periventricular, acidente vascular encefálico, infecções pré natais tais como toxoplasmose, rubéola, citomegalovírus. Nas causas pós-natais destacam-se meningite, encefalite viral, hidrocefalia, traumas, infecções, alterações vasculares.

No entanto, para Virna ${ }^{5}$, a parte motora da PC envolve alguns fenômenos negativos, como fraqueza, fadiga e incoordenação, espasticidade, clônus, rigidez e espasmos, os quais que podem levar à rigidez muscular, imparidade funcional e atrofia, se esses déficits não forem tratados eles podem evoluir para fibrose muscular, contraturas e deformidades musculoesqueléticas, ainda é observado as alterações na sensação, percepção, cognição, comunicação e comportamento, além de crises convulsivas e problemas musculoesqueléticos secundários.

Ribeiro $^{6}$ afirma que a PC é classificada a partir do comprometimento motor em espástica, discinética, atáxica e mista mesmo que as manifestações clínicas variem de acordo com o envolvimento neurológico, uma forma de classificação é o Gross Motor Function Classification System ou Sistema de Classificação da Função Motora Grossa (GMFCS), que mensura o grau funcional na PC, avaliando dentro de cinco níveis variantes, de acordo com o GMFCS a diminuição da função motora e as limitações funcionais observadas nas crianças com PC no seu movimento ao sentar e caminhar indicam a necessidade tecnologia assistiva e de dispositivos de suporte, sendo cadeiras de rodas e andadores. Para Ireno ${ }^{7}$, a visão dos profissionais com relação ao uso das órteses é de que a criança se via satisfeita com o equipamento já que o acometimento das disfunções motoras havia sofrido diminuição, já o parecer dos cuidadores e/ou responsáveis é diferente, onde eles indicam que as órteses geram dor e incômodo pelo calor excessivo produzido pelo equipamento e que as de MMSS prejudicava as áreas de ocupação da criança, como o divertimento. Para um bom resultado devemos levar em consideração a percepção daqueles que vivenciam todas as áreas da criança além do indicativo científico.

Diante de uma enfermidade que compromete a QV do indivíduo, o objetivo do presente estudo foi verificar na literatura, evidências sobre as prescrições de órteses para crianças com paralisia cerebral.

\section{Metodologia}

Trata-se de uma revisão narrativa de literatura. $O$ estudo foi construído respeitando as seguintes etapas: a) elaboração da pergunta norteadora; b) busca na literatura; c) coleta de dados; d) análise crítica dos estudos incluídos; e) discussão dos resultados; f) apresentação da revisão.

A pergunta que norteou o presente estudo foi a seguinte: "Quais órteses são utilizadas em crianças com paralisia cerebral?" Foi realizado levantamento bibliográfico nas bases de dados Literatura Latino-americana em Ciências da Saúde (LILACS), Scientific Electronic Library Online (SciELO), Public Medline (PubMed) e Physiotherapy Evidence Database (PEDro), e um livro de referência no assunto, sobre o assunto de interesse publicado no período de 2006 a 2020.

A seleção dos artigos foi realizada entre abril e maio de 2020, por todos os pesquisadores envolvidos de forma independentes utilizando os descritores nos idiomas inglês e português. Os 
descritores selecionados para a busca dos artigos foram: Fisioterapia, Paralisia cerebral infantil e Órteses. Onde foram utilizados também o conector booleano "AND". Os estudos foram selecionados inicialmente pela leitura de título e resumo. Em sequência foi realizada a leitura de texto completo, para garantia ou não da adequação aos critérios de inclusão. Foi realizada uma síntese de cada estudo, trazendo suas principais informações.

Os critérios de inclusão dos artigos da presente revisão foram: publicações completas em periódicos nacionais e internacionais; artigos que abordassem a temática do estudo, ou seja, o uso de órteses em crianças com paralisia cerebral. Os critérios de não inclusão envolveram as publicações duplicadas e pesquisas que contemplassem a utilização de órteses em indivíduos não pediátricos com paralisia cerebral ou crianças com paralisia cerebral que não utilizassem órteses para tratamento fisioterapêutico.

Figura 1: Fluxograma da revisão da literatura

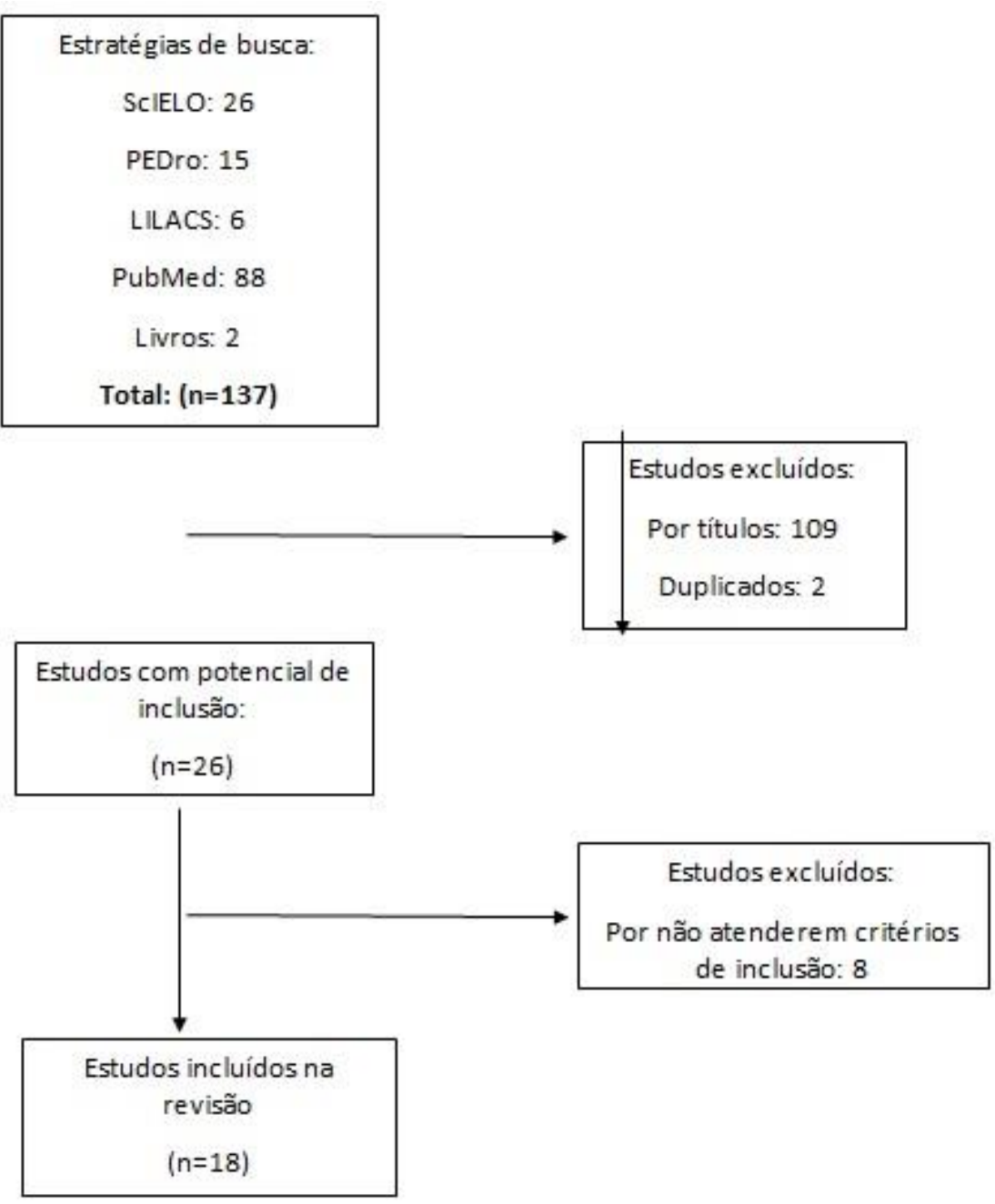




\section{Resultados e discussão}

A percepção de Sposito $^{8}$ é que ao indicar uma órtese para um paciente com paralisia cerebral, tem de se ter na cabeça os objetivos que almeja alcançar com essa indicação. De modo geral, certifica-se que as funções para órteses na paralisia cerebral são: aprimorar a função; prevenir deformidades; fornecer estabilidade; ajudar no controle seletivo motor; conter a espasticidade; preservar a extremidade no pós-operatório; estabilizar o tronco em caso de coletes. Outro aspecto indispensável para a indicação das órteses é dominar distintamente o nível funcional do paciente, para atingir uma programação cuidadosa para a utilização adequada das órteses. Na Tabela 1, estão indicadas as prescrições de órteses para membros inferiores.

Tabela 1: Tipos, prescrição e uso de órteses dos Membros Inferiores

\begin{tabular}{|c|c|c|}
\hline TIPOS DE ÓRTESES & PRESCRIÇÃO/INDICAÇÃO & USO \\
\hline Triângulo de abdução & $\begin{array}{l}\text { Controle de espasticidade e após } \\
\text { o alongamento cirúrgico. }\end{array}$ & $\begin{array}{l}\text { Uso diurno nas } 3 \text { primeiras } \\
\text { semanas, sendo retirada apenas } \\
\text { para atividades e higiene, após } \\
\text { esse período recomenda-se o } \\
\text { uso noturno. }\end{array}$ \\
\hline Twister cables & Pacientes diplégicos espásticos. & Uso em curto ou longo prazo. \\
\hline Sling & $\begin{array}{l}\text { Prescrições restritas, porém, } \\
\text { semelhante a Twister cables. }\end{array}$ & Uso em curto ou longo prazo. \\
\hline KAFO & $\begin{array}{l}\text { Pacientes com hiperextensão do } \\
\text { joelho e com flexão grave. }\end{array}$ & Uso no período de 6-12 meses. \\
\hline Talas do lona ou Splints & $\begin{array}{l}\text { Indicada para imobilizar os } \\
\text { joelhos no pós-operatório de } \\
\text { alongamento miotensinoso dos } \\
\text { isquiostibiais, como também } \\
\text { auxiliares ortostáticos para } \\
\text { promover estabilidade do joelho. }\end{array}$ & Uso noturno. \\
\hline AFO sólida & $\begin{array}{l}\text { Pacientes com PC na fase pré- } \\
\text { deambulatória, como também } \\
\text { para pacientes que não tem } \\
\text { controle seletivo motor mínimo } \\
\text { na dorsiflexão. }\end{array}$ & $\begin{array}{l}\text { Usado no período dos } 18-30 \\
\text { meses de vida da criança. }\end{array}$ \\
\hline AFO articulada & $\begin{array}{l}\text { Pacientes com níveis GMFCS I a } \\
\text { III. }\end{array}$ & $\begin{array}{l}\text { Usada em crianças de } 2 \text { e meia a } \\
4 \text { anos, beneficiando a } \\
\text { permissão da dorsiflexão, porém } \\
\text { mantendo a flexão plantar } \\
\text { bloqueada em 0․ }\end{array}$ \\
\hline
\end{tabular}


Continuação.

\begin{tabular}{|c|c|c|}
\hline AFO sólida de ração ao solo & $\begin{array}{l}\text { Indicada para o controle da } \\
\text { marcha. }\end{array}$ & $\begin{array}{l}\text { Utilizadas em crianças acima de } \\
25 \mathrm{~kg} \text {, geralmente a partir dos } 8 \\
\text { anos. }\end{array}$ \\
\hline AFO de reação ao solo articulada & $\begin{array}{l}\text { Indicada no pós-operatório } \\
\text { imediato de reconstrução de pé } \\
\text { e de alongamentos } \\
\text { miotendinosos. }\end{array}$ & $\begin{array}{l}\text { Usada em crianças acima de } \\
25 \mathrm{~kg} \text { por } 6 \text { meses, podendo } \\
\text { passar mais tempo. }\end{array}$ \\
\hline AFO tipo leaf spring & $\begin{array}{l}\text { Portadores de hemiplegia } \\
\text { espástica, com nível funcional } \\
\text { GMFCS I e II e que apresentam } \\
\text { pé equino sem deformidades. }\end{array}$ & Utilizada para deambulação. \\
\hline $\begin{array}{l}\text { SMO e UCBL (Órteses para os } \\
\text { pés - Supramaleolar) }\end{array}$ & $\begin{array}{l}\text { Indicado para inibir } \\
\text { deformidades, } \\
\text { articulação subtalar e controlar } \\
\text { valgo ou varo, portadores de } \\
\text { hipotonia e ataxias. }\end{array}$ & $\begin{array}{l}\text { Utilizada para auxiliar na } \\
\text { marcha, sendo utilizado no } \\
\text { sapato, porém, não há tantas } \\
\text { evidências cientificas sobre o } \\
\text { uso. }\end{array}$ \\
\hline
\end{tabular}

Fonte: Elaborada pelos autores com base em Carvalho ${ }^{9}$.

Na Tabela 2, estão as indicadas de órteses para membros superiores.

Tabela 2: Tipos, prescrição e uso de órteses dos Membros Superiores

\begin{tabular}{|c|c|c|}
\hline TIPOS DE ÓRTESES & PRESCRIÇÃO/INDICAÇÃO & USO \\
\hline Órtese de posicionamento & $\begin{array}{l}\text { Indicada no período pós } \\
\text { operatório imediato, para } \\
\text { proteger estruturas, como } \\
\text { também para prevenção de } \\
\text { deformidades. }\end{array}$ & $\begin{array}{l}>30 \text { dias - Uso integral, sendo } \\
\text { retirada apenas para exercícios } \\
\text { ativos resistidos. } \\
<30 \text { dias - Utilizada em repouso } \\
\text { noturno, sendo retirada várias } \\
\text { vezes ao dia para exercícios } \\
\text { tanto passivos como ativos. }\end{array}$ \\
\hline Órtese dorsal & $\begin{array}{l}\text { Indicada para pós operatório } \\
\text { imediato e tardio. }\end{array}$ & $\begin{array}{l}\text { Utilizada para uso mais } \\
\text { prolongado que a de } \\
\text { posicionamento, pois permite } \\
\text { estímulo sensorial durante o } \\
\text { uso. }\end{array}$ \\
\hline Cock-Up & $\begin{array}{l}\text { Prescrita para estabilização de } \\
\text { punho em posição funcional. }\end{array}$ & $\begin{array}{l}\text { É utilizada após o período da } \\
\text { órtese de posicionamento. }\end{array}$ \\
\hline Órtese de abdução do polegar & Pacientes quadriplégicos & Uso prolongado no período em \\
\hline
\end{tabular}


Continuação.

\begin{tabular}{|c|c|c|c|}
\hline$\stackrel{\mathscr{\sim}}{\underset{\sim}{*}}$ & & hemiplégicos espásticos. & $\begin{array}{l}\text { que a criança está de repouso } \\
\text { ou não está sendo estimulada } \\
\text { funcionalmente. }\end{array}$ \\
\hline $\begin{array}{l}\bar{\sigma} \\
\stackrel{0}{0} \\
\stackrel{8}{0}\end{array}$ & TLSO & $\begin{array}{l}\text { É indicada dependendo do grau } \\
\text { de deformidade ou tolerância ao } \\
\text { controle de tronco. }\end{array}$ & $\begin{array}{l}\text { Deve ser usada no período em } \\
\text { que a criança esteja sentada. }\end{array}$ \\
\hline & LSO & $\begin{array}{l}\text { Pacientes com PC com dor } \\
\text { lombar aguda. }\end{array}$ & $\begin{array}{l}>3 \text { meses - Usada de forma } \\
\text { integral, sendo retirada apenas } \\
\text { para banho e higiene. } \\
<3 \text { meses - Deve ser usada } \\
\text { apenas durante o dia por mais } \\
\text { 2-3 meses. }\end{array}$ \\
\hline
\end{tabular}

Fonte: Elaborada pelos autores com base em Carvalho ${ }^{9}$.

Referente a denominação das órteses, usa-se para as extremidades inferiores e para as órteses de tronco (coletes) uma intitulação vinda do inglês, em que a terminologia está associada às articulações que a órtese controla. Como por exemplo a AFO, que é um tipo de órtese que controla as articulações do pé e do tornozelo, também conhecida como órtese suropodálica. As órteses de membros superiores admitem a intitulação mais comparada à sua função, como órtese de abdução do polegar, ou, às vezes, usase uma nomenclatura própria já distinta pelo uso $^{8}$.

$\mathrm{Na}$ Tabela 3, relatamos cinco estudos e seus desfechos observacionais no uso de órteses por crianças com Paralisia cerebral. 


\begin{tabular}{|c|c|c|c|c|}
\hline AUTOR & AMOSTRA & OBJETIVO & TIPO DE ÓRTESE & RESULTADO \\
\hline Roque $^{10}$ & 15 crianças & $\begin{array}{l}\text { Analisar o equilíbrio } \\
\text { estático de crianças PC } \\
\text { diparéticas, com e sem o } \\
\text { uso de } \\
\text { suropodálicas. }\end{array}$ & $\begin{array}{l}\text { Órteses } \\
\text { suropodálicas. }\end{array}$ & $\begin{array}{llr}\text { Refletiu } & \text { em } & \text { menor } \\
\text { oscilação, ou } & \text { seja, em } \\
\text { melhor } & & \text { equilíbrio } \\
\text { estático. } & & \end{array}$ \\
\hline Silva ${ }^{11}$ & 35 crianças & $\begin{array}{l}\text { Realizar um levantamento } \\
\text { sobre os tipos e as } \\
\text { características de utilização } \\
\text { das órteses pelas crianças } \\
\text { com paralisia cerebral } \\
\text { atendidas no setor de } \\
\text { pediatria do Centro de } \\
\text { Reabilitação Física (CRF) da } \\
\text { Universidade Estadual do } \\
\text { Oeste do Paraná (Unioeste). }\end{array}$ & $\begin{array}{l}\text { Todas as órteses } \\
\text { de membros } \\
\text { inferiores para } \\
\text { pacientes com } \\
\text { PC. }\end{array}$ & $\begin{array}{l}\text { Foi capaz de identificar } \\
\text { que a órtese mais } \\
\text { utilizada pelas crianças } \\
\text { com PC atendidas no } \\
\text { setor de estudo foi a } \\
\text { suropodálica sem } \\
\text { articulação. }\end{array}$ \\
\hline Cury $^{12}$ & 20 crianças & $\begin{array}{l}\text { Comparar a marcha e o } \\
\text { desempenho motor grosso } \\
\text { de crianças portadoras de } \\
\text { PC em duas situações: sem } \\
\text { órtese e com órtese. }\end{array}$ & $\begin{array}{l}\text { Órteses } \\
\text { suropodálicas. }\end{array}$ & 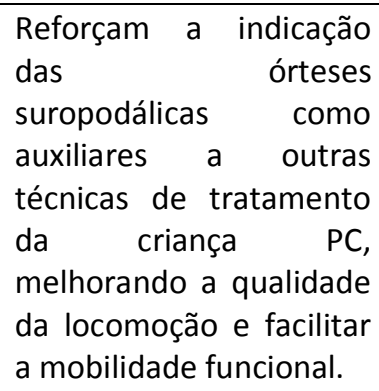 \\
\hline Rodrigues $^{13}$ & 1 criança & $\begin{array}{l}\text { Documentar os efeitos da } \\
\text { órtese de abdução do } \\
\text { polegar na amplitude de } \\
\text { movimento ativa de } \\
\text { articulações da mão e na } \\
\text { função manual de uma } \\
\text { criança com idade de três } \\
\text { anos com hemiparesia } \\
\text { espástica leve. }\end{array}$ & $\begin{array}{l}\text { Órtese } \\
\text { abdução } \\
\text { polegar. }\end{array}$ & $\begin{array}{l}\text { O uso da órtese de } \\
\text { abdução do polegar teve } \\
\text { um efeito significativo na } \\
\text { melhora da amplitude de } \\
\text { movimento da mão na } \\
\text { criança com paralisia } \\
\text { cerebral espástica } \\
\text { hemiparética leve. }\end{array}$ \\
\hline Barroso $^{14}$ & 32 crianças & $\begin{array}{l}\text { Avaliar a amplitude de } \\
\text { movimento, força muscular } \\
\text { e habilidade manual } \\
\text { utilizando as Órtese } \\
\text { Extensora de Punho e } \\
\text { Abdutora de Polegar } \\
\text { Inovada (EPAPI). }\end{array}$ & $\begin{array}{l}\text { Órtese } \\
\text { Extensora de } \\
\text { Punho r e } \\
\text { Abdutora de } \\
\text { Polegar Inovada } \\
\text { (EPAPI). }\end{array}$ & $\begin{array}{l}\text { Avaliou-se a influência } \\
\text { da órtese EPAPI nas } \\
\text { variáveis de ADMs } \\
\text { estática e dinâmica da } \\
\text { ATMC, força muscular e } \\
\text { habilidade manual. }\end{array}$ \\
\hline
\end{tabular}

Fonte: Os autores (2020).

\section{Conclusão}

O desenvolvimento do presente estudo possibilitou uma análise da importância do conhecimento sobre a patologia abordada, de acordo com a necessidade individual de cada criança, permitindo fazer prescrição de uma órtese como tratamento fisioterapêutico para as mesmas.

Os objetivos para a prescrição de uma órtese para crianças com paralisia cerebral de uma forma geral é, a melhora da função motora já que esse é a principal característica da PC, prevenir possíveis deformidades, prover estabilidade, controlar a espasticidade, auxiliar no controle de tronco e proteger extremidades no pós-operatório.

Foram vistas que há inúmeros tipos de órteses e com o levantamento deste estudo, pode-se observar que as mais indicadas são as AFOs, contudo faz-se necessário que mais estudos sejam realizados, com melhores qualidades metodológicas e que tenham como desfecho o efeito das órteses em paciente com 
paralisia cerebral infantil para poder embasar e difundir o uso mais preciso por fisioterapeutas, como também para as crianças e acompanhantes e elucidar essa problemática.

\section{Referências}

1. SOUZA, C.R.D.; GIROTTI, P.A.; ZUTTIN, F.D.S. Orientações quanto à utilização de órtese para membros inferiores em crianças com paralisia espástica. Faculdade de ciências sociais e agrárias de Itapeva - FIAT., 2014.

2. MIURA, T.R., PETEAN, L.B.E. Paralisia cerebral grave: o impacto na qualidade de vida de mães cuidadoras. Mudanças - Psicologia da Saúde., v. 20, n 1-2, p.7-12, Jan/Dez., 2012.

3. OLIVEIRA, A. C. T.; BALLARINO, H.; MONTEIRO, M. R.; PINTO, N. A.; PIRES, E. L. S. R. Análise da visão e forma de colocação de órtese tornozelo- pé pelos pais ou cuidadores de pacientes com paralisia cerebral. Ver Bras Clin Med, São Paulo, v. 8, n. 6, p. 490-494, nov./dez. 2010.

4. ROTHSTEIN, J.R, BELTRAME, T.S. Características motoras e biopsicossocias de crianças com paralisia cerebral. R. bras. Ci. e Mov., v. 21, n 3, p.118-126, 2013.

5. VIRNA, C.F.R., ISLENE, B.V., MARIA, Z.C.F.D., ELIZABETH, M.M., MÔNICA, R.S.B. EVIDÊNCIAS CIENTÍFICAS ACERCA DA PARALISIA CEREBRAL INFANTIL Cogitare Enfermagem, v. 18, n. 4, p. 796-802, Out/Dez., 2013.

6. RIBEIRO, S.D., OLIVEIRA, D.D.N.M., AMORIM, R.C., BOTELHO, M.S., MASCARENHAS, M.H.C., MATOS, T.M.J., SANTOS, M.I., REIS, D.S.M., REBOUÇAS, D.J. Alterações músculo esqueléticas em crianças com paralisia cerebral no município de Jeque - Bahia. Universidade Estadual do Sudoeste da Bahia-UESB., 2017.

7. IRENO, J.M., CHEN, N., ZAFANI, M.D., BALEOTTI, L.R. O uso de órteses em crianças com paralisia cerebral: percepção dos cuidadores. Cad. Bras. Ter. Ocup., v. 27, n. 1, p. 35-44, 2019.

8. SPOSITO, M. M. M. Cirurgia e intervenções físicas o tratamento da espasticidade na paralisia cerebral. ACTA FISIÁTRICA, São Paulo, v. 17, n. 2, p. 84-91, 2010.

9. CARVALHO, J. A. Utilização de órteses no tratamento de paralisia cerebral e mielomeningocele na visão da ortopedia pediátrica. In: CARVALHO, J. A. Órteses - Um recurso terapêutico complementar. 2a ed. São Paulo: Manole, 2013. p.104-130.

10. ROQUE, A. H.; KANASHIRO, M. G.; KAZON, S.; GRECCO, L. A. C.; SALGADO, A. S. I.; OLIVEIRA, C. S. Análise do equilíbrio estático em crianças com paralisia cerebral do tipo diparesia espástica com e sem uso de órteses. Fisioterapia Mov., Curitiba, v. 25, n. 2, p. 311-316, abr/jun. 2012.

11. SILVA, D. O.; PAZZINATTO, M. F.; TOMADON, A.; FERREIRA, A. J. M.; MEIRELES, A.; SILVA, J. A. O. Caracterização das órteses utilizadas por crianças com paralisia cerebral atendidos no centro de reabilitação física em Cascavel-PR. Rev. de Atenção à Saúde, v. 13, n. 43, p. 18-22, jan/mar. 2015.

12. CURY, V. C. R.; MANCINI, M. C.; MELO, A. P.; FONSECA, S. T; SAMPAIO, R. F.; TIRADO, M. G. A. Efeitos do uso de órteses na mobilidade funcional de crianças com paralisia cerebral. Revista Brasileira de Fisioterapia, Belo Horizonte, v. 10, n. 1, p. 67-74, 2006.

13. RODRIGUES, A. M. V. N.; MANCINI, M. C.; VAZ, D. V.; SILVA, L. C. Uso de órteses para abdução do polegar no desempenho funcional de criança portadora de paralisia cerebral: Estudo de caso único. Rev. Bras. Saúde Matern. Infant., Recife, v. 7, n. 4, p. 423-436, 2007.

14. BARROSO, P.N. Nova órtese de extensão de punho e abdutora de polegar para crianças com paralisia cerebral: Avaliação de suas contribuições para o incremento da funcionalidade manual. 2010. Trabalho de pós graduação (Doutorado em bioengenharia) Universidade Federal de Mina Gerais, Belo Horizonte, 2010.

\section{Endereço para Correspondência}

Nome: Paulo Henrique de Melo

Endereço: Av. Mário Melo, 86, apto 204, Santo

Amaro, Recife-PE

Recebido em 03/09/2020

Aprovado em 27/02/2021

Publicado em 10/05/2021 